\title{
Can exposure to coalmine dust cause a severe impairment of lung function?
}

\author{
J F HURLEY AND C A SOUTAR
}

From the Institute of Occupational Medicine, Edinburgh EH8 9SU, UK

ABSTRACT It is well recognised that exposure to respirable coalmine dust causes a reduction in lung function but it has not been clear whether the impairment of function is sufficient to cause disability, unless progressive massive fibrosis occurs. From a study of 4059 men without progressive massive fibrosis who worked in the coal industry for at least ten years from the 1950 s, and who were $\stackrel{\vec{\omega}}{\omega}$ followed up and re-examined medically more than 20 years later, a subgroup was selected using $\dot{\omega}$ criteria intended to favour those who may have suffered greater than average effects of dust ex- $\overrightarrow{0}$ posure. These 199 men had left the coal industry before normal retiral age, had taken other jobs, and had reported symptoms of chronic bronchitis at follow up. The inverse relation between dust exposure and $\mathrm{FEV}_{1}$ among these 199 men was much more severe than the average effects previously $₹$ shown among more representative groups of coalminers. The effect of exposure to respirable dust was estimated conservatively as an impairment of about $2 \mathrm{ml} \mathrm{FEV}$ per unit of dust exposure $\left(\mathrm{gh} / \mathrm{m}^{3}\right)$. The estimated effect among ex-smokers was more severe. These compare with a previous estimate, based on a less selected population, of $0.6 \mathrm{ml} \mathrm{FEV}$, per gh/m $/ \mathrm{m}^{3}$. The new estimate in this ? group of 199 men corresponds to an average loss of $600 \mathrm{ml} \mathrm{FEV}_{1}$ in response to a moderately high dust exposure to $300 \mathrm{gh} / \mathrm{m}^{3}$, with correspondingly higher losses in the ex-smokers. These findings show that among a group of men intentionally selected to include those who may have suffered greater than average effects of dust exposure, the relation between exposure and FEV is consistent $^{\circ}$ with the view that in some men even moderately high exposure to dust causes severe impairment of lung function.

An inverse relation between exposure to respirable dust and the lung function of coalminers was established more than ten years ago ${ }^{1}$ and confirmed subsequently in other studies. ${ }^{2-4}$ The average dust effect was estimated $^{1}$ as a loss of $0.6 \mathrm{ml} \mathrm{FEV}_{1}$ per unit of dust exposure $\left(\mathrm{gh} / \mathrm{m}^{3}\right)$, implying on average a clinically modest reduction in response to a lifetime's working under current conditions in British coalmines.

There are two reasons why some men may nevertheless suffer a clinically important loss of function in response to dust exposure. Firstly, Rogan and colleagues noted that $10 \%$ of the coalface workers in their study had experienced dust exposures in excess of $440 \mathrm{gh} / \mathrm{m}^{3}$, associated on average with estimated reductions of $250 \mathrm{ml} \mathrm{FEV}{ }_{1}$ or more. ${ }^{1}$ Such high exposures are, however, extremely unlikely under today's conditions. Secondly, they also considered the unexplained differences in $\mathrm{FEV}_{1}$ among men with

Accepted 15 August 1985 moderate dust exposures. To some extent these? differences may reflect a natural variability in the way that the lung function of coalminers responds to dust $\stackrel{\Phi}{3}$ exposure. Studies to date, however, have not identified what factors, if any, may be related to a 3 . more severe response. Thus there are at present no direct estimates of the effect of dust in the men who respond most severely, and the clinical importance of 0 dust exposure for the lung function of coalminers has remained a controversial issue. ${ }^{5-7}$

While studying a group of 1867 coalminers and 2192 ex-miners in Britain in whom average dust $\widetilde{N}$ effects $^{8}$ similar to those reported previously ${ }^{1}$ were es- $N$ tablished, we aimed to characterise and to study in $N$ detail subgroups of men who are most likely to in- $\omega$ clude those suffering greater than average effects of dust exposure. One such group, certainly not repre- $\stackrel{O}{-}$ sentative of coalminers generally, included 199 men who showed an exceptionally severe inverse relation between exposure to respirable dust and $\mathrm{FEV}_{1}$. We now report the results that show this relation and dis- $\mathbb{D}$ cuss its causes and implications. A more comprehen- 
sive report is being prepared that will include other results from the larger study of which this finding forms a part.

\section{Subjects and methods}

\section{CONTEXT}

The data form part of the pneumoconiosis field research, ${ }^{9}$ in which 53382 coalminers participated between 1953 and 1980 . The men studied were included in a sample ${ }^{10}$ of 17738 coalminers examined between 1953 and 1958 at the first of a series of medical surveys of the current working populations at 24 collieries $^{9}$ throughout Britain. The 24 collieries were grouped into six geographical regions for the purposes of the present analysis.

A full sized chest radiograph was taken at all surveys. The earliest generally reliable measurements of lung function were obtained between 1963 and 1968 at the third of this series of medical surveys, attended by 8128 men in the sample who were still employed in the industry at that time. The exclusion of men with progressive massive fibrosis (PMF) at third survey, and others with missing or unreliable survey data, reduced those available for study to $7624 \mathrm{men}$. Of these, 4833 attended at a further series of follow up examinations between 1974 and 1980, aimed at reexamining survivors from the sample whether or not they were still working in the industry; $1305(17 \%)$ of the 7624 men had died. The representativeness of the 4833 men relative to the group of 8128 has been described recently. ${ }^{11}$

Further exclusions for incomplete or unreliable data or the presence of PMF at follow up survey reduced the study group from 4833 to 4059 men, of whom 2192 had left the coal industry by that time. The $\mathbf{4 0 5 9}$ men form the basis of continuing study investigating substantive and methodological aspects of the relation between dust exposure and lung function, both cross sectionally and longitudinally. The primary purpose of this work is to determine whether or not ex-miners had responded more severely to dust exposure than had the men who remained employed in the coal industry.

\section{DA TA}

Questionnaires on respiratory symptoms and smoking habits were administered by trained personnel at all surveys other than the first. ${ }^{12}$ Chronic bronchitis at follow up survey was defined on the basis of the questionnaire as the presence of persistent cough and persistent sputum. Lung function was measured by simple spirometry, ${ }^{1}$ and the mean of three technically satisfactory measurements of $\mathrm{FEV}_{1}$ at follow up survey used in the analysis. When only one or two technically satisfactory blows had been recorded, the mean of these was accepted. Date of birth was recorded and standard anthropometric measurements taken.

All follow up survey chest radiographs were read independently and in random order by a panel of five readers (four of whom were not medically qualified) who had trained themselves ${ }^{13}$ to interpret chest radiographs according to the ILO U/C classification. ${ }^{14}$ The median of these five readings was used as the follow up survey classification for each man.

Men were classified as current smokers, exsmokers, and lifelong non-smokers at follow up on the basis of their responses to the smoking questionnaires. Two approximate indices of cigarette consumption were derived for men who were current smokers of cigarettes only, and not pipes or cigars, at the third medical survey. Firstly, the number of cigarettes smoked at the time of third survey was multiplied by the number of years since the man was aged 16 , and expressed as a total number of cigarettes smoked. Then the number smoked at the time of follow up survey was multiplied similarly by the length of the interval between intermediate and follow up surveys. The number of cigarettes smoked during this latter interval had not been recorded for men who had given up smoking between intermediate and follow up surveys, and a value of zero cigarette consumption was assigned to them for this period.

Estimates of the dust concentrations to which men had been exposed were derived from an intensive long term programme of environmental sampling at the 24 research collieries concerned. ${ }^{15}$ Continuous monitoring of where men worked within the collieries, supplemented by occupational histories obtained by interviews at the medical surveys, provided information on the time worked by each man in these conditions. Data on concentrations and on time worked were then linked ${ }^{16}$ to provide estimates of individuals' lifetime exposures to respirable coalmine dust. The units of dust exposure are grammes of respirable dust per cubic metre of air times hours $\left(\mathrm{gh} / \mathrm{m}^{3}\right)$.

Occupational histories recorded at follow up were also used to classify the $\mathbf{4 0 5 9}$ men as miners or exminers. Ex-miners were subclassified according to whether they had retired from work, been made redundant, or left voluntarily and taken up other jobs after leaving.

\section{STATISTICAL METHODS}

After detailed data descriptions, $\mathrm{FEV}_{1}$ at follow up survey was related in cross sectional analyses to other characteristics of the men, using linear regression methods. ${ }^{17}$ Analyses were carried out using the BMDP suite of programs. ${ }^{18}$ Residuals were examined thoroughly.

We found that $\mathrm{FEV}_{1}$ level varied by geographical 
Table 1 Mean (SD) of, or number (\%) with, selected characteristics among the 199 men relative to men of similar age from the original study group of 4059 men

\begin{tabular}{|c|c|c|c|}
\hline & Subjects of this paper & Ex-miners $<65$ years* & Miners \\
\hline $\begin{array}{l}\text { No } \\
\text { Age (years) } \\
\text { Height (cm) } \\
\text { Weight (kg) } \\
\text { Dust exposure }\left(\mathrm{gh} / \mathrm{m}^{3}\right) \\
\text { FEV }(\mathrm{ml}) \\
\text { Smoking status: }\end{array}$ & $\begin{array}{c}199 \\
53(7) \\
170(6) \\
77(12) \\
158(103) \\
2492(842)\end{array}$ & $\begin{array}{l}1023 \\
56(8) \\
170(6) \\
75(13) \\
167(107) \\
2485(834)\end{array}$ & $\begin{array}{c}1867 \\
53(7) \\
170(6) \\
76(12) \\
174(100) \\
2751(759)\end{array}$ \\
\hline $\begin{array}{l}\text { Non-smokers } \\
\text { Ex-smokers } \\
\text { Smokers }\end{array}$ & $\begin{array}{c}11(6 \%) \\
35(18 \%) \\
153(77 \%)\end{array}$ & $\begin{array}{l}125(12 \%) \\
273(27 \%) \\
625(61 \%)\end{array}$ & $\begin{array}{r}255(14 \%) \\
435(23 \%) \\
1177(63 \%)\end{array}$ \\
\hline $\begin{array}{l}\text { Geographical region: } \\
\text { Scotland } \\
\text { West Midlands } \\
\text { North East England } \\
\text { Yorks and Notts } \\
\text { South Wales } \\
\text { Other }\end{array}$ & $\begin{array}{l}35(18 \%) \\
6(3 \%) \\
40(20 \%) \\
9(5 \%) \\
49(25 \%) \\
60(30 \%)\end{array}$ & $\begin{array}{c}182(18 \%) \\
75(7 \%) \\
222(22 \%) \\
68(7 \%) \\
249(24 \%) \\
227(22 \%)\end{array}$ & $\begin{array}{l}276(15 \%) \\
224(12 \%) \\
379(20 \%) \\
412(22 \%) \\
330(18 \%) \\
246(13 \%)\end{array}$ \\
\hline
\end{tabular}

region, and that its relation to age varied according to smoking habit when men were classified as non-, ex-, or current smokers. ${ }^{8}$ These factors, together with height and weight, were found to provide an adequate context in which to study the effect of dust exposure.

\section{SUBJECTS}

Analyses of the 4059 men had confirmed that there was a clear effect of dust exposure on $F E_{1}$ taking into account other factors including geographical variations. $^{8}$ There was some evidence that the 1023 ex-miners who were younger than the retirement age of 65 had suffered a more severe response to dust exposure than other men. These ex-miners were classified further according to whether or not they reported symptoms of chronic bronchitis, since men may have been influenced in decisions about jobs by perception of their health and the influence of work on it.

The results suggested a greater than average effect of dust exposure among the 453 ex-miners under 65 who had reported symptoms of chronic bronchitis. These men were therefore examined in more detail according to their reasons for leaving the industry and their subsequent employment, since such decisions could also be influenced by perceptions of health or illness.

The 453 ex-miners with bronchitic symptoms comprised 158 who had left the coal industry voluntarily and did not take other jobs, 199 men who left voluntarily and did take other work, and 96 who had been made redundant or were unclassifiable in terms of subsequent employment.

The 199 men who left voluntarily and took other work are the subjects of this paper. Results for the 158 men who left voluntarily, without taking other jobs, did not show a strong association between dust ex- posure and $\mathrm{FEV}_{1}$. They will be included in the main $ᄋ$ report of the study of 4059 men, which is in prepara- tion.

\section{Results}

The data in table 1 compare the 199 subjects with miners and ex-miners of similar age from the larger study group of $\mathbf{4 0 5 9}$ men. The three groups are similar in height and weight. The geographical distribu- $\frac{\partial}{0}$ tion of the 199 men is similar to that of other ex-miners aged under 65 but different from that of the $\frac{\mathbb{}}{\Phi}$ men who stayed in the industry.

There was no evidence (table 1) that the 199 men had experienced particularly high dust exposures. They did, however, include an unusually high propor- $-\frac{7}{0}$ tion of smokers. Nevertheless, their unadjusted FEV $\frac{1}{\circ}$ was not unusually low, on average, being almost iden- $\Phi$ tical with that of other ex-miners aged less than $65^{3}$ and, like them, worse than the $\mathrm{FEV}_{1}$ of men who had stayed in the industry.

There are, however, large variations in unadjusted FEV $_{1}$ levels within the group of 199 men. The most striking characteristic (table 2) is the association be-J tween high dust exposure and low $\mathrm{FEV}_{1}$. This effect is? pronounced in all four age groups considered, and does not appear to be explicable in terms of the height $\tilde{O}^{\circ}$ of the men concerned. In addition, the observed values of $F E V_{1}$ indicated clinically severe impairment of lung function in some men, particularly among the $\omega$ older and higher exposure groups. Five men had an? $\mathrm{FEV}_{1}$ below one litre, and three of these had experiso enced dust exposures in excess of $300 \mathrm{gh} / \mathrm{m}^{3}$.

The interpretation of an association such as shown ${ }^{?}$ in table 2 is complicated by many factors that may influence $\mathrm{FEV}_{1}$ level; in particular, the data in table $2 \stackrel{\mathrm{C}}{\mathrm{O}}$ take no account of smoking habit or geographical 
Table 2 Numbers of men, mean (SD) of FEV $(l)$, and height (cm), in 199 men grouped by ranges of age and dust exposure

\begin{tabular}{|c|c|c|c|c|c|}
\hline \multirow[t]{3}{*}{ Age (years) } & \multicolumn{5}{|c|}{ Dust exposure $\left(g h / m^{3}\right)$} \\
\hline & $0-99$ & $100-199$ & $200-299$ & $\geqslant 300$ & All \\
\hline & $\begin{array}{l}\text { No } \\
\text { FEV } \\
\text { Height }\end{array}$ & $\begin{array}{l}\text { No } \\
\text { FEV } \\
\text { Height }\end{array}$ & $\begin{array}{l}\text { No } \\
\text { FEV } \\
\text { Height }\end{array}$ & $\begin{array}{l}\text { No } \\
\text { FEV } \\
\text { Height }\end{array}$ & $\begin{array}{l}\text { No } \\
\text { FEV } \\
\text { Height }\end{array}$ \\
\hline$<50$ & $\begin{array}{c}35 \\
3.2(0.9) \\
171(6)\end{array}$ & $\begin{array}{c}23 \\
2.9(0.8) \\
171(6)\end{array}$ & $\begin{array}{c}4 \\
2.5(1.0) \\
165(7)\end{array}$ & $\begin{array}{c}2 \\
2.4(0.8) \\
172(4)\end{array}$ & $\begin{array}{c}64 \\
3.0(0.9) \\
171(6)\end{array}$ \\
\hline $50-54$ & $\begin{array}{c}9 \\
2.9(0.5) \\
172(7)\end{array}$ & $\begin{array}{c}13 \\
2.4(0.5) \\
170(5)\end{array}$ & $\begin{array}{c}11 \\
2 \cdot 1(0 \cdot 6) \\
170(3)\end{array}$ & $\begin{array}{c}6 \\
2 \cdot 1(0 \cdot 9) \\
171(5)\end{array}$ & $\begin{array}{c}39 \\
2.4(0.6) \\
171(5)\end{array}$ \\
\hline $55-59$ & $\begin{array}{c}20 \\
2 \cdot 5(0 \cdot 7) \\
170(5)\end{array}$ & $\begin{array}{c}23 \\
2 \cdot 1(0 \cdot 7) \\
170(5)\end{array}$ & $\begin{array}{c}17 \\
2 \cdot 4(0 \cdot 6) \\
171(7)\end{array}$ & $\begin{array}{c}5 \\
1.8(0 \cdot 7) \\
170(4)\end{array}$ & $\begin{array}{c}65 \\
2 \cdot 3(0 \cdot 7) \\
170(6)\end{array}$ \\
\hline$>60$ & $\begin{array}{c}9 \\
2.2(0.9) \\
172(8)\end{array}$ & $\begin{array}{c}7 \\
2 \cdot 1(0 \cdot 7) \\
169(13)\end{array}$ & $\begin{array}{c}10 \\
1.9(0 \cdot 5) \\
170(7)\end{array}$ & $\begin{array}{c}5 \\
1.4(0.8) \\
168(8)\end{array}$ & $\begin{array}{c}31 \\
1.9(0.7) \\
170(9)\end{array}$ \\
\hline All & $\begin{array}{c}73 \\
2.9(0.9) \\
171(6)\end{array}$ & $\begin{array}{c}66 \\
2 \cdot 5(0 \cdot 8) \\
170(6)\end{array}$ & $\begin{array}{c}42 \\
2 \cdot 2(0 \cdot 6) \\
170(7)\end{array}$ & $\begin{array}{c}18 \\
1.8(0 \cdot 8) \\
170(5)\end{array}$ & $\begin{array}{c}199 \\
2.5(0.8) \\
170(6)\end{array}$ \\
\hline
\end{tabular}

variations. A strong inverse relation between dust exposure and $\mathrm{FEV}_{1}$ was, however, confirmed $(\mathrm{t}=$ $-4 \cdot 1, \mathrm{p}<0.001)$ in multiple regression analyses that adjusted simultaneously for the effects of age, height, weight, differences between smoking groups (including different effects of age according to smoking habit), and regional differences. The regression coefficients are given in table 3 and help to explain the structure of the statistical representation. Note that in terms of statistical significance, a relation of $F E V_{1}$ is established more clearly with dust exposure than with any other single characteristic.

We next examined in several different ways whether or not changes in the data or in the statistical representation led to substantial changes in the estimated relation of $F E V_{1}$ to dust exposure.

Firstly, we checked if the association was due to the presence of a few men with high dust exposures and low lung function. Four such men (mean age 59; dust exposure $524 \mathrm{gh} / \mathrm{m}^{3} ; \mathrm{FEV}_{1} 867 \mathrm{ml}$ ) were excluded from an analysis that was otherwise identical with that in table 3. In this context the estimated regression coefficient of $\mathrm{FEV}_{1}$ on dust exposure was somewhat more conservative, at $-2.0 \mathrm{ml} \mathrm{FEV}, \mathrm{per} \mathrm{gh} / \mathrm{m}^{3}$ of exposure, but remained highly significant statistically $(t=-2.9, \mathrm{p}<0.01)$.

Secondly, we considered it plausible that we might adjust more reliably for age, height, weight, smoking status, and regional differences by estimating their influence using data from all 4059 miners and exminers, rather than from the smaller subgroup of 199 men. When this was done, and using a representation otherwise identical with table 3 , the more conservative estimate of the dust $\mathrm{FEV}_{1}$ relation was confirmed in size and in statistical significance.

Thirdly, we investigated if the estimated effects of dust exposure were sensitive to the way in which smoking effects were represented. These analyses were

Table 3 Coefficients from the regression of $F E V_{1}(\mathrm{ml})$ on other characteristics of the 199 men

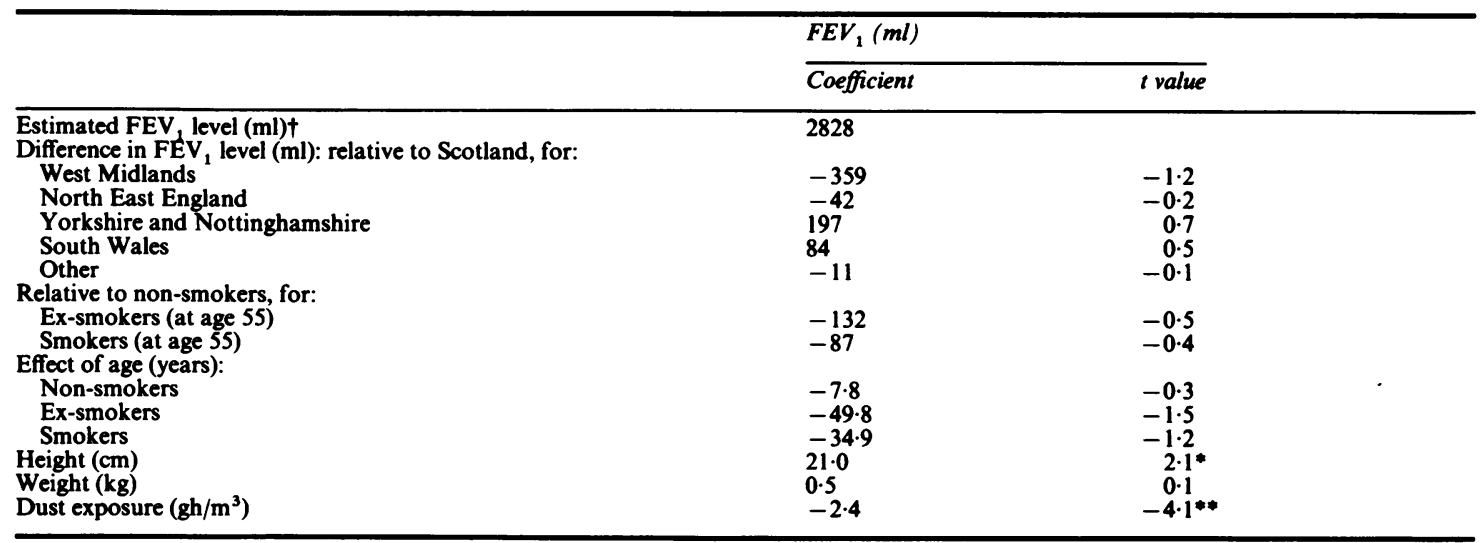

$0.01<\mathrm{p}<0.05 ; *{ }^{*} \mathrm{p}<0.001$.

†For non-smoker in Scotland, age 55, height $170 \mathrm{~cm}$, weight $75 \mathrm{~kg}$. 
restricted to the 163 men for whom approximate indices of cigarette consumption were available, comprising 11 lifelong non-smokers and 152 men who at third survey smoked cigarettes only. Several representations were investigated.

(1) The effect of dust was estimated as $-2.7 \mathrm{ml}$ $\mathrm{FEV}_{1} / \mathrm{gh} / \mathrm{m}^{3}(t=-4 \cdot 3)$ when the influence of smoking was represented simply as average differences between the three smoking groups, with concomitant adjustments for age, height, weight, and geographical region.

(2) The added inclusion of the two indices of cigarette consumption did not contribute significantly to the fit of the model in this small group, and the size and statistical significance of the estimated dust effect remained unaltered. (Estimates of the numbers of cigarettes smoked were found to be related to FEV in the larger group of $\mathbf{4 0 5 9}$ men.)

(3) The effect of smoking was next represented by different losses of $\mathrm{FEV}_{1}$ with age in the three smoking groups, in addition to differences between the groups. In this context the effect of dust was estimated as $-2.6 \mathrm{ml} \mathrm{FEV} / \mathrm{gh} / \mathrm{m}^{3}(t=-4.0)$.

(4) When all the representations of smoking effect, including the indices of cigarette consumption, were simultaneously taken into account along with the other characteristics of table 3 , the dust effect was estimated as $-2.5 \mathrm{ml} \mathrm{FEV} / \mathrm{gh} / \mathrm{m}^{3}(t=-3.9)$.

Clearly, the estimated dust effect was insensitive to which representation was used.

Finally, we considered whether, within the group of 199 men, the estimated effect of dust exposure varied according to smoke habit. Table 4 gives the characteristics of the men, grouped by smoking status at follow up survey. Few (7\%) of the 199 men showed simple pneumoconiosis of category 2 or higher.

Data descriptions indicated that the 35 ex-smokers may have experienced a particularly severe effect of dust exposure. Regression analyses similar to those carried out for all 199 men were applied separately to the smokers and ex-smokers, and confirmed this im- pression. For example, when the influences of age, $\overline{3}$ height, weight, smoking status, and regional $\stackrel{\odot}{?}$ differences were estimated using data for all $4059 \mathrm{~min}-\stackrel{\vec{\Rightarrow}}{\Rightarrow}$ ers and ex-miners, then the inverse relation between $\stackrel{5}{\rightarrow}$ dust exposure and $\mathrm{FEV}_{1}$ among the 35 ex-smokers was estimated as a reduction of $3.1 \mathrm{ml} \mathrm{FEV}$ per unit of exposure $(t=-4.5, \mathrm{p}<0.001)$. The estimated $\frac{5}{5}$ response was even more severe when the 199 men, or $\stackrel{\triangleright}{\unrhd}$ the 35 ex-smokers themselves, formed the basis for age and other adjustments.

Three of the four men with high dust exposures and low lung function, noted above, were ex-smokers. When these three men were excluded from the analysis the estimated dust effect among ex-smokers remained substantial, at a reduction of $2.5 \mathrm{ml} \mathrm{FEV}_{1}$ per $\mathrm{gh} / \mathrm{m}^{3}$ of exposure, but the statistical significance was reduced to the $8 \%$ level $(t=-1 \cdot 8)$.

The clinical effects may be illustrated using the conservative estimate of an average reduction of $2.0 \mathrm{ml}$ $\mathrm{FEV}_{1}$ per $\mathrm{gh} / \mathrm{m}^{3}$ dust exposure among the $199 \mathrm{men}$. This corresponds to an impairment of $316 \mathrm{ml}$ of FEV in an ex-miner who had experienced the average dust exposure of the group, or an impairment of $600 \mathrm{ml}$ in response to an exposure of $300 \mathrm{gh} / \mathrm{m}^{3}$, a moderately high exposure for this group of men. Note, however, that the greatest exposure experienced was more than twice as high, at $629 \mathrm{gh} / \mathrm{m}^{3}$. These losses are additional to those caused by aging and smoking, and almost certainly underrepresent the experience of the ex-smokers.

\section{Discussion}

Exposure to respirable dust is known to impair the lung function of coalminers. ${ }^{1-48}$ On average, the reductions in $\mathrm{FEV}_{1}$ are clinically modest in response to exposures experienced in Britain over a working lifetime. $^{18}$ Nevertheless, to understand whether exposure to coalmine dust may lead to disability even in

Table 4 Mean (SD) of, or number (\%) with, selected characteristics among the 199 men, by smoking category

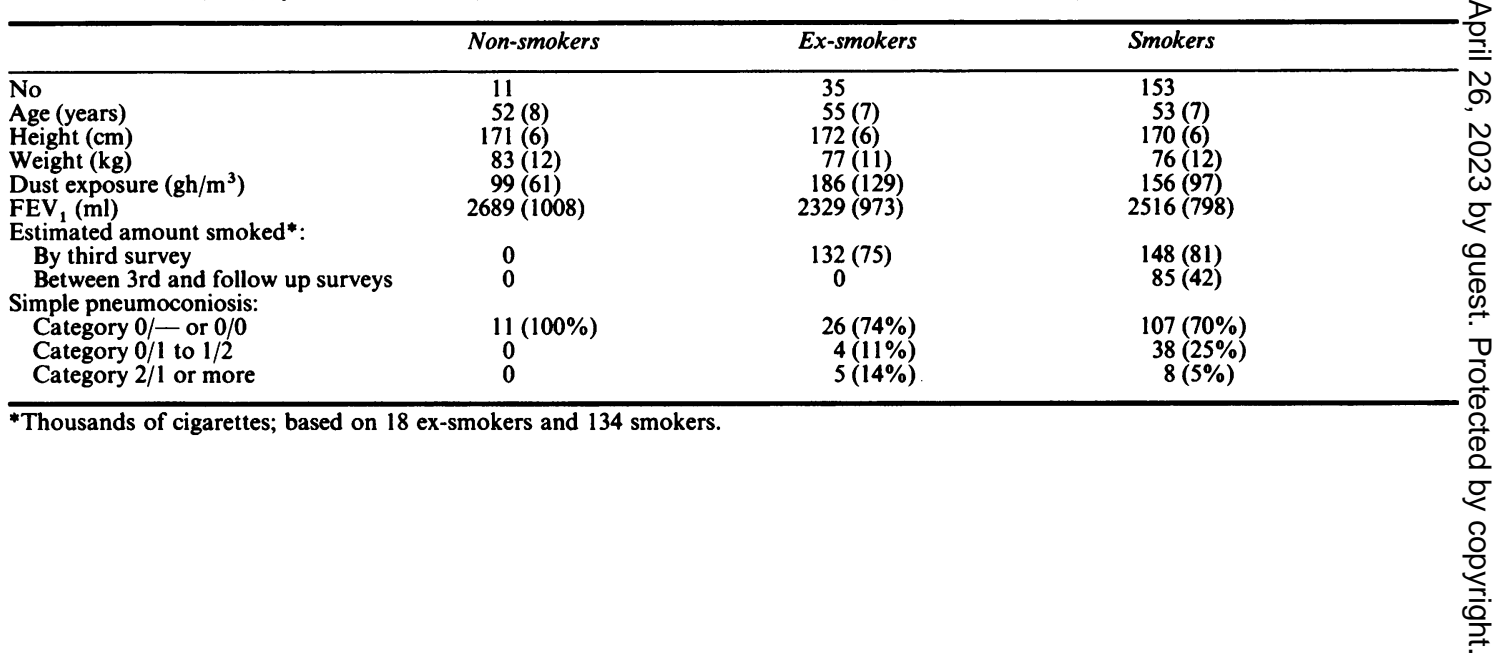


the absence of progressive massive fibrosis information is required about the severity of response in the more susceptible men. To date, such evidence has not been available.

The broad aim of the analysis reported here was to investigate the issue of susceptibility within a study group of $\mathbf{4 0 5 9}$ miners and ex-miners. Our specific objective was to identify and study a group of men selected by criteria that favoured those who may respond more severely than average to the effects of dust exposure. This objective has been attained. An unusually severe inverse relation between dust exposure and lung function, more than three times that for less selected groups of coalminers ${ }^{18}$ has been established unambiguously among the 199 subjects of this paper. The estimated relation is sufficiently severe that if a cause and effect interpretation is legitimate, we may conclude that dust exposure can lead to severe impairment of lung function in coalminers, other than through the medium of progressive massive fibrosis.

Before discussing the central issue of how to interpret this finding, we wish to emphasise that the 199 subjects of this report are certainly not representative of coalminers generally. This is implicit in the objectives of the analysis, and follows also from the way in which the subgroup was selected. The 199 men are characterised by a combination of health and employment patterns which suggested that they, particularly, might have responded more severely than normal to dust exposure. Specifically, they had left the coal industry voluntarily before normal retirement age, and reported symptoms of chronic bronchitis when reexamined subsequently at medical surveys. Recent studies have shown that men leaving prematurely from another dusty industry had suffered a more rapid decline in $\mathrm{FEV}_{1}$ than their fellow workers, thus lending some support to the criteria we adopted. ${ }^{19}$

Note that the selection procedure did not produce a group of men with unusually high dust exposures, nor

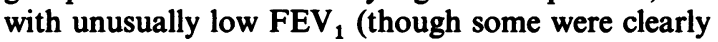
clinically ill). What was distinctive was the strength and severity of the association between $\mathrm{FEV}_{1}$ and dust exposure in the subgroup studied. This association was evident in the data descriptions, and was confirmed by more formal statistical methods. Thus we are dealing with a group which was atypical in

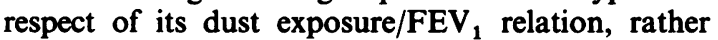
than in either of these characteristics alone.

In interpreting the finding of an extreme relation we think it important to recall that the rationale underlying this analysis, and indeed the entire research programme of which it is a part, ${ }^{9}$ is that dust exposure may cause lung damage. Generally, a cause and effect relation between dust exposure and respiratory health is well accepted. Against this background, the most straightforward interpretation of our results is that the dust related reductions in lung function were in fact a health effect of exposure to dust. We think that this view is correct.

Other explanations are less convincing. The result did not arise from an undue influence of a few men with low lung function and high dust exposures (though even such a limited finding might point to an unusually severe response). Rather, the relation found reflected an experience of the group as a whole. Nor was the result an artefact due to some curious inter-relation between dust exposure and other influential characteristics-for example, age. Our estimation of adjustments for age and other factors using data from all $\mathbf{4 0 5 9}$ men guarded against such a possibility. Nor is there any evidence that smoking was the real cause. The many different ways of representing the effect of smoking all led to the same conclusions about the relation of dust exposure to $\mathrm{FEV}_{1}$.

There were, however, relatively few non-smokers among the 199 men. Possibly smoking influenced the inclusion of men in the group we selected through its influence on symptoms of chronic bronchitis and on lung function insofar as this may have been a reason for job changes. Generally, the average effect of dust exposure is not altered by smoking ${ }^{178}$ and further analyses of the larger group of $\mathbf{4 0 5 9}$ men are therefore planned to determine whether unusually severe effects of dust on FEV 1 can occur in non-smokers also.

The second smoking related issue concerns why exsmokers responded more severely than other men. The reasons are not obvious. It may be that some men, recognising a deterioration of respiratory health, took what precautions they could both by stopping smoking and leaving the industry. Or it is possible that stopping smoking in some way accelerated the effect of dust exposure in $F E V_{1}$ and this is another aspect which we will investigate further when we study the $\mathbf{4 0 5 9}$ men longitudinally.

We know of no other factors which might reasonably be considered a cause of the unusual exposure response relation. The final possibility is that the result we found is a freak and essentially a meaningless one, the chance outcome of circumstances which, if they could be repeated, would show nothing of interest. Results from a small simulation exercise, reported in the appendix, suggest that such an event is extremey unlikely. In our view the evidence is strongly in favour of the simple interpretation that dust exposure caused the lung function impairment.

It is natural then to consider why some men responded severely to dust exposure whereas others did not. One possibility is that the 199 men may have been exposed to environmental influences, at work or elsewhere, different from their colleagues. Or there may be questions of individual susceptibility. We 
have not attempted to investigate these issues because the main purpose of the present work has been the more limited objective of seeing whether a severe re-

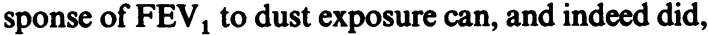
occur.

It is natural also to consider whether men experiencing an extreme response are rare in the coal industry. Again, a full answer goes beyond what we have attempted at this stage. It is noteworthy, however, that the 199 subjects of the present paper comprised only $5 \%$ of the larger study group from which they were selected. On the other hand, that larger group of 4059 men had worked in the coal industry for about 11 years from the 1950 s onwards. Some men who began to show a severe response may have left the industry in that period and so could not be included in these analyses. Thus $5 \%$, as a crude estimate of the proportion of men susceptible to a severe response, may be too low.

In addition, many of those who respond most severely may not experience sufficient dust exposure to cause an important impairment of function. This was so even among the 199 men we studied. All were ex-miners; an effect, and perhaps a purpose, of leaving the industry was to limit their exposure to dust. Also, the men studied experienced the greater part of their exposure to dust in the 1960 s or earlier, when dust concentations were often higher than is now permitted. The maximum exposure likely during a working life under current dust regulations in British mines has been estimated at $245 \mathrm{gh} / \mathrm{m}^{3} .^{20}$ The impairment

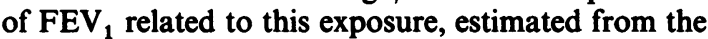
results for all 199 men considered here, would be on average about $490 \mathrm{ml}$, or about $760 \mathrm{ml}$ in the exsmokers. These also would be clinically important losses, though it is unlikely that any men would actually experience this maximum exposure as most of men's working lifetimes are currently spent in dust levels well below the maximum permissible.

In conclusion, we see the atypical experience of this group of men somewhat in terms of a case study. The fact that such an extreme relation can and did occur is important, especially since the most reasonable explanation is that it signifies a clinically important effect

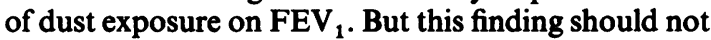
overshadow the well established result that on average the response of $F E V_{1}$ to dust exposure is clinically modest, and that severe lung damage from exposure to respirable dust is likely to be rare.

This work was supported by the Commission of the European Communities (Contract No 7246-16/8/002) and by the National Coal Board of Great Britain. We also gratefully acknowledge the contribution of many colleagues towards the large study of which this is a small part. In particular we should like to thank DC
Gurr and HPR Collins for help with data or- $\frac{3}{8}$ ganisation and statistical analyses.

\section{Appendix}

We carried out a limited exercise to describe the relation between dust exposure and FEV among small $_{1}$ randomly selected subgroups of the $\mathbf{4 0 5 9}$ men, relative to that of a larger and more representative sub- os group.

Each of the 4059 men was allocated at random and with equal probability to one of 116 groups whose average size of 35 was identical to that of the exsmokers in this paper. Thirty five of the groups, again selected at random, were combined into a single large set with which results from the other $\mathbf{8 1}$ groups could be compared. Linear regression analyses of FEV 1 were then carried out among all $\mathbf{4 0 5 9}$ men using a representation as in table 3 but extended to provide distinct estimates of FEV 1 level and of dust exposure in each of the 82 groups. This entire process of group construction and regression analysis was repeated three times, giving in all 243 comparisions of dust effect in a small subset with that of a larger combined group.

The effect of dust was estimated from the large combined groups as $-0.78,-0.61$, and $-0.65 \mathrm{ml}$ FEV 1 per $\mathrm{gh} / \mathrm{m}^{3}$ exposure on the three occasions respectively and was highly significant statistically. In six $(2.5 \%)$ of the 243 subgroups the estimated effect differed from this average by $-2.0 \mathrm{ml} \mathrm{FEV}_{1}$ per $\mathrm{gh} / \mathrm{m}^{3}$ or more; while in only one of the 243 groups $\overrightarrow{\vec{\sigma}}$ was the estimated effect greater than $-3.1 \mathrm{ml} 3$ $\mathrm{FEV}_{1} / \mathrm{gh} / \mathrm{m}^{3}$, the value estimated among ex-smokers in this paper.

\section{References}

${ }^{1}$ Rogan J, Attfield MD, Jacobsen M, Rae S, Walker DD, Walton $\bar{\sigma}$ WH. Role of dust in the working environment in development of 3 . chronic bronchitis in British coal miners. $\mathrm{Br} J$ Ind Med 1973;30:217-26.

${ }^{2}$ Reichel G, Ulmer WT. Results obtained by the Bochum research group. In: Chronic bronchitis and occupational dust exposure. 음 Boun: Deutsche Forschungsgemeinschaft, 1978:224-91.

${ }^{3}$ Hankinson JL, Reger RB, Fairman RP, Lapp NL, Morgan WKC. Factors influencing expiratory flow rates in coal miners. In: Walton WH, ed. Inhaled particles IV. Oxford: Pergamon Press, N 1977:737-55

${ }^{4}$ Love RG, Miller BG. Longitudinal study of lung function in $\mathrm{N}$ coalminers. Thorax 1982;37:193-7.

${ }^{5}$ Anonymous. Occupation and bronchitis (Editorial). Lancet $\mathrm{W}$ 1980;i:235-6.

${ }^{6}$ Morgan WKC, Lapp NL, Seaton D. Respiratory disability in coalminers. JAMA 1980;243:2401-4.

${ }^{7}$ Jacobsen M. Smoking and disability in miners. Lancet 1980;i:740. $\mathbb{D}$

${ }^{8}$ Soutar CA, Hurley JF, Gurr DC. The relationship between dust ? $^{+}$ exposure and lung function in miners and ex-miners. In: Bergbau-Berufsgenossenschaft. VIth International Pneu- $\bar{O}$ moconiosis Conference 1983, Bochum. Geneva: International La- $\mathbb{D}$ bour Organisation, 1984:390-6. 
${ }^{5}$ Rogan JM, Rae S, Walton WH. The National Coal Board's pneumoconoisis field research, an interim review. In: Inhaled particles and vapours II. Oxford and New York: Pergamon Press, 1966:493-508.

${ }^{10}$ Maclaren WM, Soutar CA. Progressive massive fibrosis and simple pneumoconiosis in ex-miners. Br J Ind Med 1985;42:734-40.

${ }^{11}$ Gauld SJ, Hurley JF, Miller BG. The effect of non-response in a longitudinal study of coalminers' respiratory health and exposure to dust. In: Inhaled particles VI. Oxford: Pergamon Press (in press).

${ }^{12}$ Rae S, Walker DD, Attfield MD. Chronic bronchitis and dust exposure in British coal mines. In: Walton WH, ed. Inhaled particles III. Old Woking (Surrey) 1971: Unwin Bros: 883-94.

${ }^{13}$ Copland L, Burns J, Jacobsen M. Classification of chest radiographs for epidemiological purposes by people not experienced in the radiology of pneumoconiosis. $\mathrm{Br} J$ Ind Med 1981;38:254-61.

${ }^{14}$ International Labour Office. ILO U/C classification of radiographs of the pneumoconioses, 1971. Geneva: ILO, 1972. (Occupational safety and health series No 22.)
${ }^{15}$ Dodgson J, Hadden GG, Jones CO, Walton WH. Characteristics of the airborne dust in British coal mines. In: Walton WH, ed. Inhaled particles III. Old Woking (Surrey): Unwin Bros, 1970: 757-81.

${ }^{16}$ Hurley JF, Burns J, Copland L, Dodgson J, Jacobsen M. Coalworkers' simple pneumoconiosis and exposure to dust at 10 British coalmines. Br J Ind Med 1982;39:120-7.

${ }^{17}$ Draper NR, Smith H. Applied regression analysis. 2nd ed. New York: John Wiley and Sons, 1981.

${ }^{18}$ Dixon WJ, ed. BMDP statistical software. Los Angeles: University of California Press, 1981.

${ }^{19}$ Eisen EA, Wegman DH, Louis TA. Effects of selection in a prospective study of forced expiratory volume in Vermont granite workers. Am Rev Respir Dis 1983;128:587-91.

${ }^{20}$ Jacobsen M. Coalworkers' pneumoconiosis: results from epidemiological studies in Britain. In: BergbauBerufsgenossenschaft. VIth International Pneumoconiosis Conference 1983, Bochum. Geneva: International Labour Organisation, 1984:92-102. 